\title{
The interface between rhetoric and layout in multimodal artefacts
}

\section{Hiippala, Tuomo}

\section{3}

Hiippala , T 2013 , ' The interface between rhetoric and layout in multimodal artefacts ' , Literary and Linguistic Computing , vol. 28 , no. 3 , pp. 461-471 . https://doi.org/10.1093/llc/fqs064

http://hdl.handle.net/10138/40260

https://doi.org/10.1093/llc/fqs064

acceptedVersion

Downloaded from Helda, University of Helsinki institutional repository.

This is an electronic reprint of the original article.

This reprint may differ from the original in pagination and typographic detail.

Please cite the original version. 
NB! Author's version: do not cite!

This is a pre-copy-editing, author-produced PDF of an article accepted for publication in Literary $8 \mathcal{G}$ Linguistic Computing following peer review. The definitive publisher-authenticated version is available online at: http://dx.doi.org/10.1093/llc/fqs064

If you do not have access to Literary $\&$ Linguistic Computing, contact me for a copy of the article. My contact details may be found here: http://bit.ly/IYTyUQ 


\title{
The interface between rhetoric and layout in multimodal artefacts
}

\author{
Tuomo Hiippala \\ Department of Modern Languages \\ University of Helsinki
}

\begin{abstract}
This research-in-progress report describes ongoing work on a doctoral dissertation, which attempts to model the prototypical structure of the tourist brochure as a multimodal artefact. By using a multimodal corpus based on the Genre and Multimodality model, the dissertation investigates how the brochures use both language and image to fulfil their communicative function. This paper focuses on a specific aspect of the prototypical structure, that is, how the brochures organize the content in the layout and signal its interrelations.

The paper suggests that the layout and the rhetorical relations between the content are intertwined in what may be called the 'rhetoric-layout interface'. By drawing on a sample of three brochures published in 1984, 1988 and 2006, the paper explores how this interface shapes multimodal structure of the tourist brochures. The relationship between the rhetorical and the layout structure is suggested to be reciprocal: adopting a particular configuration in the rhetorical structure also affects the range of choices available in the layout structure and vice versa.

The paper concludes that the interface between the rhetorical and the layout structure warrants attention in modelling the prototypical structure, and suggests that certain structural signals related to the use of twodimensional space require specific attention in corpus analysis. Moreover, extensive cross-layer analyses with larger corpora will be required to tease out the range of different configurations in the tourist brochures, in order to create a prototypical model of the multimodal artefact.
\end{abstract}




\section{Introduction}

The introduction of digital technologies to the study of humanities has brought about new possibilities for both analysis and theory-building. This also applies to the field of multimodal research, which studies language and image as modes, that is, as resources for making and exchanging meanings. Faced with a complex and extensive domain of research, researchers working with multimodality have already acknowledged the potential of digital technologies. For instance, digital corpora and analytical tools are expected to bring increased analytical reliability and empiricism to the developing field (see e.g. Bateman et al. 2004, Parodi 2010, O'Halloran et al. 2010, 2011, Smith et al. 2011).

New theories of multimodality are also taking shape. For instance, Elleström (2010) and Bateman (2011) have introduced increasingly fine-grained definitions of mode, which is a fundamental concept within multimodal research. As the term 'multimodal' implies, any instance of multimodal phenomena involves multiple interacting modes, which need to be deconstructed if we wish to understand their contribution to multimodality. Traditionally, mode has been understood as a "socially shaped and culturally given resource for meaning making" (Kress 2009, p. 54). This means that the co-deployed modes, such as language and image, are shaped by both social situation and culture.

However, despite our increasing knowledge of multimodality, many questions about the modes and how they are used remain open. For example, Forceville (2007, p. 1236) identifies the lack of 'top-down conceptualizations' to support the detailed multimodal analyses as a particular point of concern. In this paper, I discuss these 'conceptualizations' by using the notion of 'abstract descriptions'. I use the notion to discuss approaches that seek to describe the generic principles behind multimodality, which may also apply to other multimodal phenomena than the individual artefact or situation currently under analysis.

In this research-in-progress report, I address one aspect of these abstract descriptions by drawing on the ongoing work on my doctoral dissertation. I aim to show that the organization of verbal and visual content in a layout and the signalling of their interrelations involves semiotic choices that mutually affect each other. In addition, I propose that this 'rhetoric-layout interface' may also influence the way we recognize multimodal artefacts and interact with them. The structure of the paper is as follows: the initial discussion focuses on the prevalent theories of multimodality and their analytical foci. I then proceed to discuss the rhetoriclayout interface with three examples, before concluding with a discussion of the analysis. 


\section{From detailed to abstract descriptions}

Before discussing the more abstract semiotic levels in multimodal analysis, it is necessary to identify the major theories of multimodality and to evaluate their capability to produce abstract descriptions. Jewitt (2009) identifies three major approaches to multimodal analysis: social semiotic multimodality (hereafter SSM), systemic-functional multimodal discourse analysis (hereafter SF-MDA) and multimodal interactional analysis. For current purposes, I focus on SSM (van Leeuwen 2005a, Kress \& van Leeuwen 2006, Kress 2010) and SF-MDA (O'Halloran 2004, 2008), both of which draw on the work of the linguist M.A.K. Halliday on social semiotics and systemic-functional linguistics (see e.g. Halliday 1978, Halliday \& Matthiessen 2004).

A central feature of both SSM and SF-MDA is the notion of metafunctions, which proposes that a semiotic resource fulfills three simultaneous functions in each instance of its use. O'Halloran (2008, p. 444) writes:

The metafunctional principle is the principle that semiotic resources simultaneously provide the tools for constructing ideational meaning (i.e. experiential meaning and logical relations) and for enacting social relations (i.e. interpersonal meaning). These metafunctions are enabled through the organization of discourse, which is the textual metafunction of semiosis.

O'Halloran (2008) suggests that semiotic resources, such as language and image, can be modelled on the basis of metafunctions. Indeed, the metafunctions allow a detailed analysis of multimodal meaning-making, as the extensive use of the concept shows. In SSM and SF-MDA, the metafunctional configurations of meaning have been studied, for example, in picture books (Guijarro \& Pinar Sanz 2008, Guijarro 2011), biology textbooks (Guo 2004), magazine advertisements (Royce 1998, Cheong 2004, O'Halloran \& Lim 2009), street posters (White 2010), tourist brochures (Hiippala 2007, Kvåle 2010, Francesconi 2011), cooking recipes and computer manuals (Martinec 2003). The metafunctional principle has also been used to describe the meaning potential of colour (Kress \& van Leeuwen 2002, van Leeuwen 2011), architecture (O'Toole 2010), space (Stenglin 2009) and museum exhibitions (Hofinger \& Ventola 2004).

However, as Jewitt (2009, p. 17) points out — at least within SSM - the metafunctional principle has been applied mainly in case studies:

[W]ithin the social semiotic approach to multimodality, the metafunctions are generally used as a conceptual tool to describe and explore the semiotic resources and meaning potential that people use to make meaning rather than to map the system itself. 
This means that SSM has prioritized case studies over mapping the range of possible choices in the semiotic resources, that is, the entire system. Nevertheless, both SSM and SF-MDA have also explored the more abstract semiotic levels. As van Leeuwen (2005b, p. 73) writes:

We need to know more both about the extent to which different modes can do the same kind of communicative work and about the extent to which they differ in their semiotic potential, and we need to know more about the difference between doing the same kind of communicative work through one mode or through another. But what is also needed is research on the way different modes are integrated in multimodal texts.

What is thus required is a considerable effort to bridge the gap between detailed analyses and the more abstract descriptions, which may be used to map the possible configurations of the semiotic resources. The complexity of the studied phenomenon sets certain prerequisites for this task: (1) the capability to deconstruct and systemically describe the semiotic resources and (2) the collection and analysis of data in sufficiently large quantities. The latter requirement (2) will be discussed later in Section 3. To meet the requirement set out in (1), I suggest we use the notion of a semiotic mode as defined by Bateman (2011).

Bateman (2011) proposes a tri-stratal model of a semiotic mode to capture its operation: these strata are (1) material substrate, (2) semiotic resources and (3) discourse semantics. A material substrate emerges over time, as it establishes itself as a suitable carrier of semiotic resources, which may be manipulated by a group of users. Contemporary examples of a material substrate include paper and screen: these material substrates enable the semiotic resources to take a permanent form.

The next stratum - the semiotic resources — is described using syntagmatic and paradigmatic axes of organization. According to Bateman (2011, p. 20), the semiotic resources, such as language and image, combine "paradigmatic systems of choice together with a syntagmatic organization for re-expressing the paradigmatic choices in structural configurations". This implies that the semiotic resources provide a range of choices ("saying this or saying that") and combine these choices into larger structures. Finally, the discourse semantics component guides the contextual interpretation of the semiotic resources by providing the candidate interpretations in each context (Bateman 2011, p. 21).

Furthermore, Bateman (2009) identifies three semiotic modes in print media: text-flow, image-flow and page-flow. Text-flow consists of linear-interrupted text, which may be interrupted by images, diagrams and tables. This article, for example, relies mainly on text-flow to communicate its meanings. In print media, static image-flow organizes graphical elements into meaningful sequences. Finally, page-flow uses the two-dimensional space to distribute the content and to signal its 
interrelations (Bateman forthcoming, p. 10). The use of the entire two-dimensional space is a defining feature of page-flow, which may also combine both text-flow and image-flow in its expression.

The example of a biology textbook in Kress (2009, pp. 59-64) finely illustrates how pages organize language and image into coherent wholes. However, the 'redesigned', incoherent example (Kress 2009, p. 63) also illustrates our need to be able to say more about the actual reasons behind the perceived incoherence. Hiippala (2012b, p. 321-323) discusses similar examples of diagrams within page-flow in a Finnish biology textbook from the perspective of semiotic modes (cf. Bateman 2011). Contrasted with rather self-evident descriptions of 'columns of writing and image' and 'blocks' in Kress (2009, p. 62), the notion of semiotic modes provides the means to make formalized and structurally-grounded statements about the semiotic resources and their interpretation, whose validity across different contexts may be then evaluated. I argue that this capability is a prerequisite for advancing into abstract descriptions of multimodality, which are discussed below.

\section{Abstract descriptions of multimodal artefacts}

In previous research, various approaches have been adopted to explore the more abstract semiotic levels in multimodal analysis. Particularly, the notions of genre and generic structure have been frequently used for this purpose. For instance, van Leeuwen (1993) pointed out the need to study the generic structure of multimodal artefacts already at an early stage; he later followed up by deploying the notion of genre to describe the functionality of page-based artefacts in print and digital media (van Leeuwen 2005b). Cheong (2004), in turn, presented a generic model of a print advertisement with a specific account of ideational meanings and their functions in the advertisements. Finally, Held (2005) studied magazine covers as a multimodal genre, whose function is to attract the reader's attention and showcase the magazine contents. To sum up, the main contribution of the previous research has been the observation that the structure of multimodal artefacts appears to be functionally motivated. However, dedicated analytical tools are required if we wish to explore this phenomenon further.

One candidate for exploring the structure and functionality of multimodal artefacts is the Genre and Multimodality model, which aims to describe the structure of multimodal documents by drawing on previous work in linguistics, document design and genre research (hereafter abbreviated as GeM; see Delin et al. 2003, Bateman et al. 2004, Bateman 2008). The GeM model intends to provide a set of tools for reproducible and evaluable analyses of any given multimodal artefact (Bateman 2008, p. 2). Previously, the model has been used to analyze multimodal phenomena in cross-cultural contexts (see e.g. Thomas 2009b, Hiippala 2012a), and 
its XML-based annotation schema has been explored in connection with concordancers (Thomas 2007) and eye-tracking (Hiippala 2012b). While the scope of this paper does not allow an in-depth description of the GeM model, the model may still be used to explore the interface between layout and rhetorical structure within the framework of genre.

Bateman (forthcoming, p. 5) asserts that effective genre analysis needs to be supported by a well-formed theory of multimodal structure; that is, genre analysis needs to be grounded in structure. Therefore, Bateman (2008, p. 229) argues that intuitive genre labels, such as 'newspaper' and 'guide book', are not sufficiently accurate and establish artificial boundaries. However, the recognition of these artefacts suggests that certain mechanisms exist to distinguish between different artefacts. For this purpose, I propose the notion of a prototype, which draws on the notion of genre to establish the range of allowed configurations for a particular artefact.

The GeM model theorizes the existence of a 'genre space', whose boundaries are established by the genre structures, that is, by the selections made in the semiotic modes (Bateman 2008, p. 244-5). In this connection, the idea that similar configurations of semiotic modes may be found in the underlying genre structure of different multimodal artefacts deserves a closer look. Although Bateman (2008, p. 229) argues against the use of layperson terms to classify multimodal artefacts or genres, the existence of concepts such as 'tourist brochure', 'tourist guide', 'user manual' and 'direct mail advertisement' suggests that the artefacts have certain prototypical characteristics, which enable their recognition and invoke particular models of inference and interpretation established during previous encounters with similar artefacts.

To illustrate the issue, I recently presented a group of undergraduate students with three different multimodal artefacts: a page-sized magazine advertisement, a double-page from an elementary school biology textbook (see Hiippala 2012b, p. 321) and a double-page from a tourist brochure (see Fig. 1). Following Reichenberger et al. (1996), the resolution of each example was reduced from 300 DPI to 20 DPI, thus rendering the text unreadable, but retaining sufficient detail to distinguish between verbal and visual elements, their combinations and organization in the layout.

The students recognized the different artefacts relatively quickly, also in the case of the tourist brochure, which could be suggested to be a multimodal artefact that they do not interact with on a daily basis. It appears that the explicit features of a multimodal artefact may provide the reader with cues about its functionality (cf. Holsanova \& Nord 2010, p. 83). It is unlikely, however, that these cues would be purely visual, that is, exclusively related to the appearance of a layout. Instead, I suggest that these cues may be influenced by the semiotic modes and 


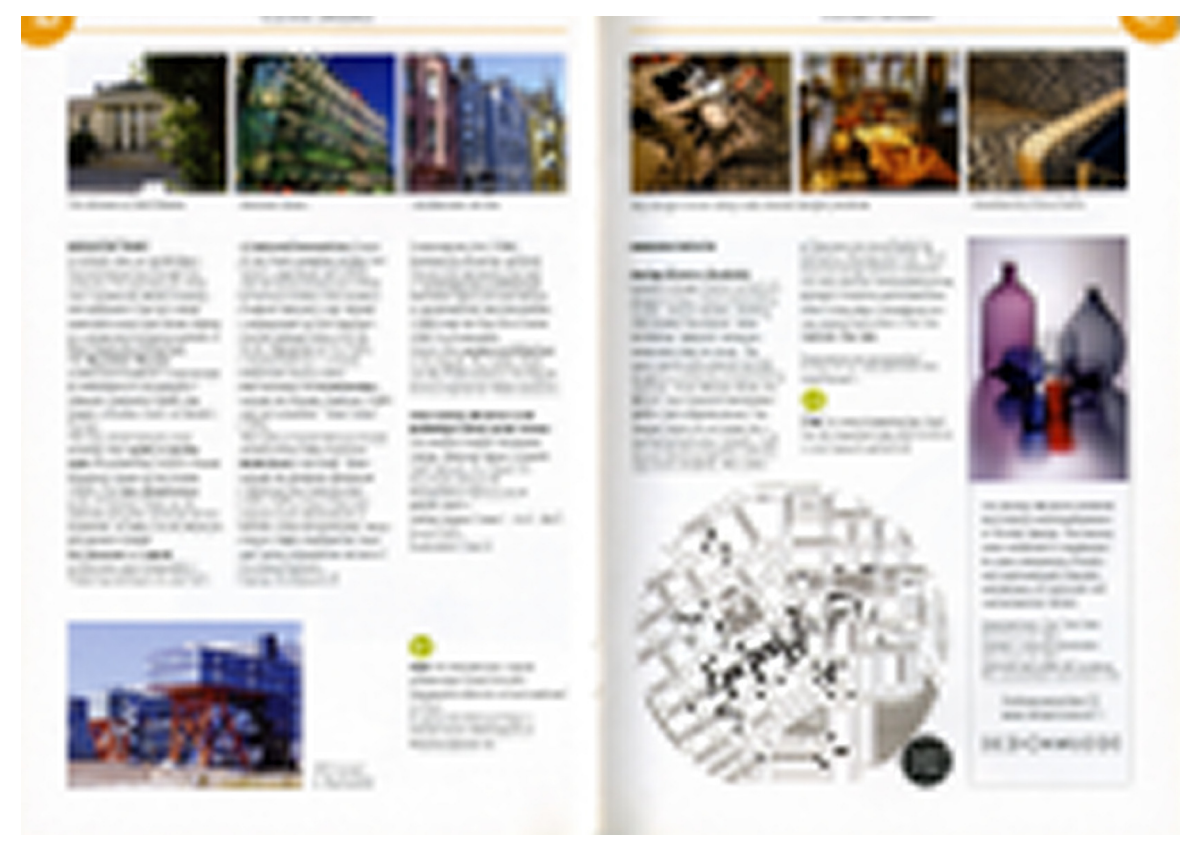

Fig. 1 A double-page from Helsinki Your Way (2006) at 20 DPI

their discourse semantic interpretation. In the following subsections, I discuss two interrelated aspects of multimodal structure that may contribute to the recognition process.

\subsection{The use of two-dimensional space on the page}

The first issue to be discussed is the use of the two-dimensional space on the page. As a material substrate, the page allows the organization of semiotic modes in various ways, as shown in Figs. 2, 3 and 4. Each figure shows a representation of the physical layout - the so-called 'area model' in GeM terms (cf. Bateman 2008, p. 125-129). The grey areas indicate areas with text-flow. As Figs. 2, 3 and 4 show, the tourist brochures may adopt several different layout configurations to fulfill the same communicative function.

However, layout constitutes only a single aspect of the multimodal structure of the tourist brochures. Therefore, layout alone is not sufficient for formulating generic statements about their multimodal structure. As Thomas (2009a, 45-46) has pointed out, exceedingly abstract generalizations about layout rarely hold: as a complex phenomenon, layout needs to be observed from multiple perspectives. For instance, layout may contribute to the interpretation of image-text combinations (cf. Martinec \& Salway 2005, Kong 2006). In the case of images and captions in Fig. 3, spatial proximity translates into rhetorical unity: the discourse semantic 


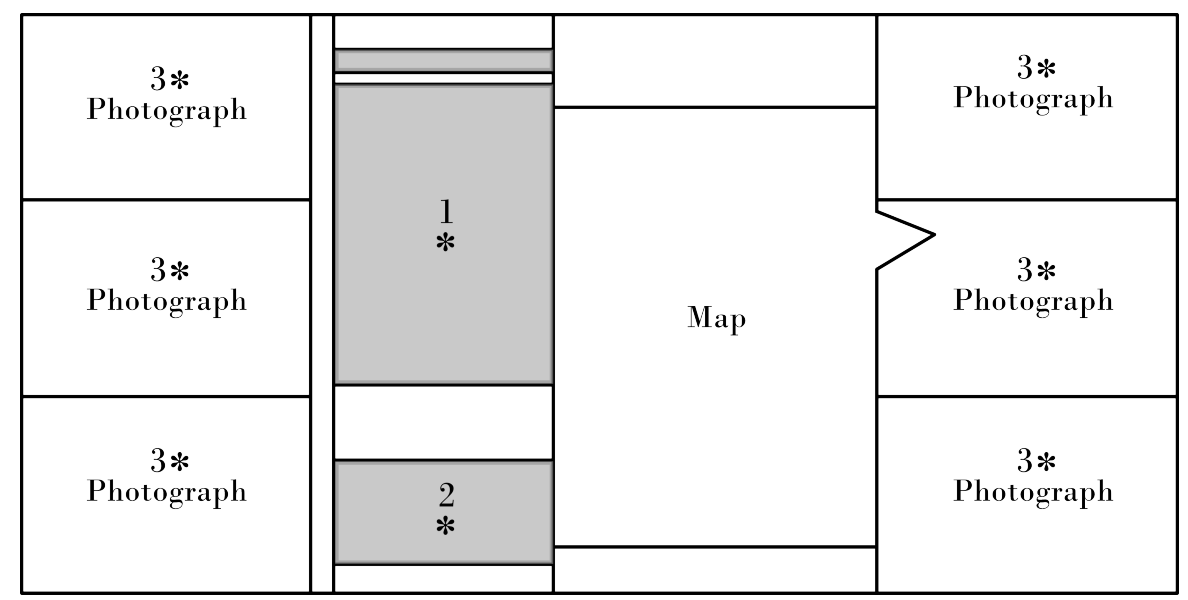

Fig. 2 Helsinki's Four Tourist Islands (1984)

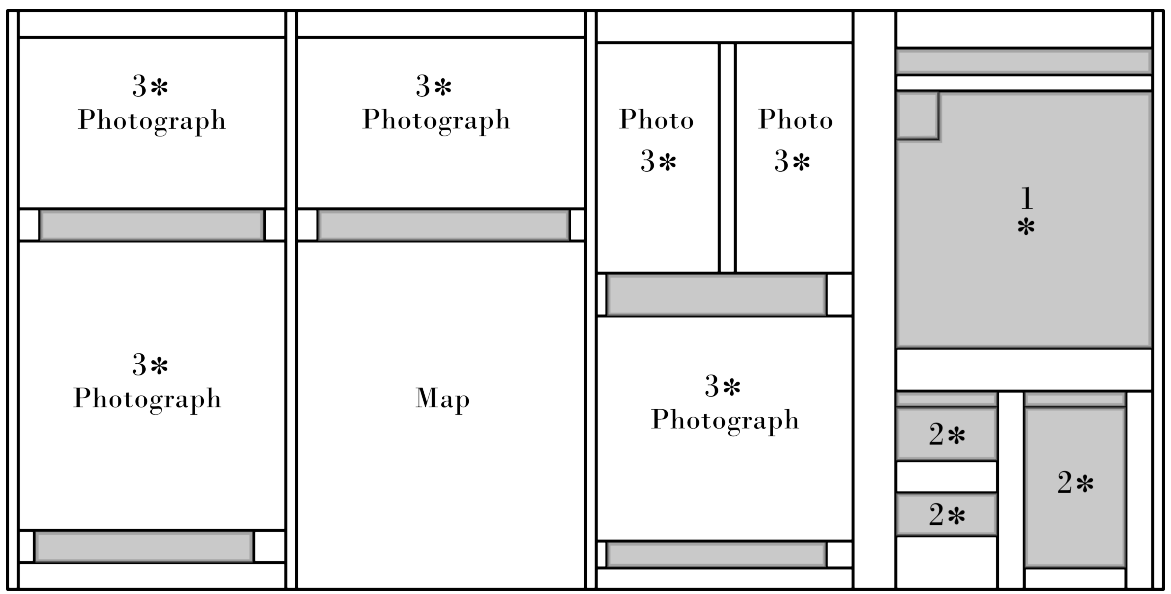

Fig. 3 Helsinki's Four Tourist Islands (1988)

interpretation of these images and their captions is formalized in Fig. 5 (for a discussion and examples of formalizations, see Bateman 2011, Hiippala 2012b).

The second issue relates to the 'visual turn' in communication. Kong (2006, p. 222) discusses the image-text relations in another form of tourism discourse, that is, in travel guides, whose development he characterizes as follows:

Travel guides exhibit a range of styles, from content that is extremely packed with words without any pictures to content that is fully illustrated with images and pictures. This reflects the history of the genre - texts produced more than 10 years ago tend to be more word-based, whereas those produced in the last 5 years are usually illustrated with more pictures and images, although the degree of integration between 


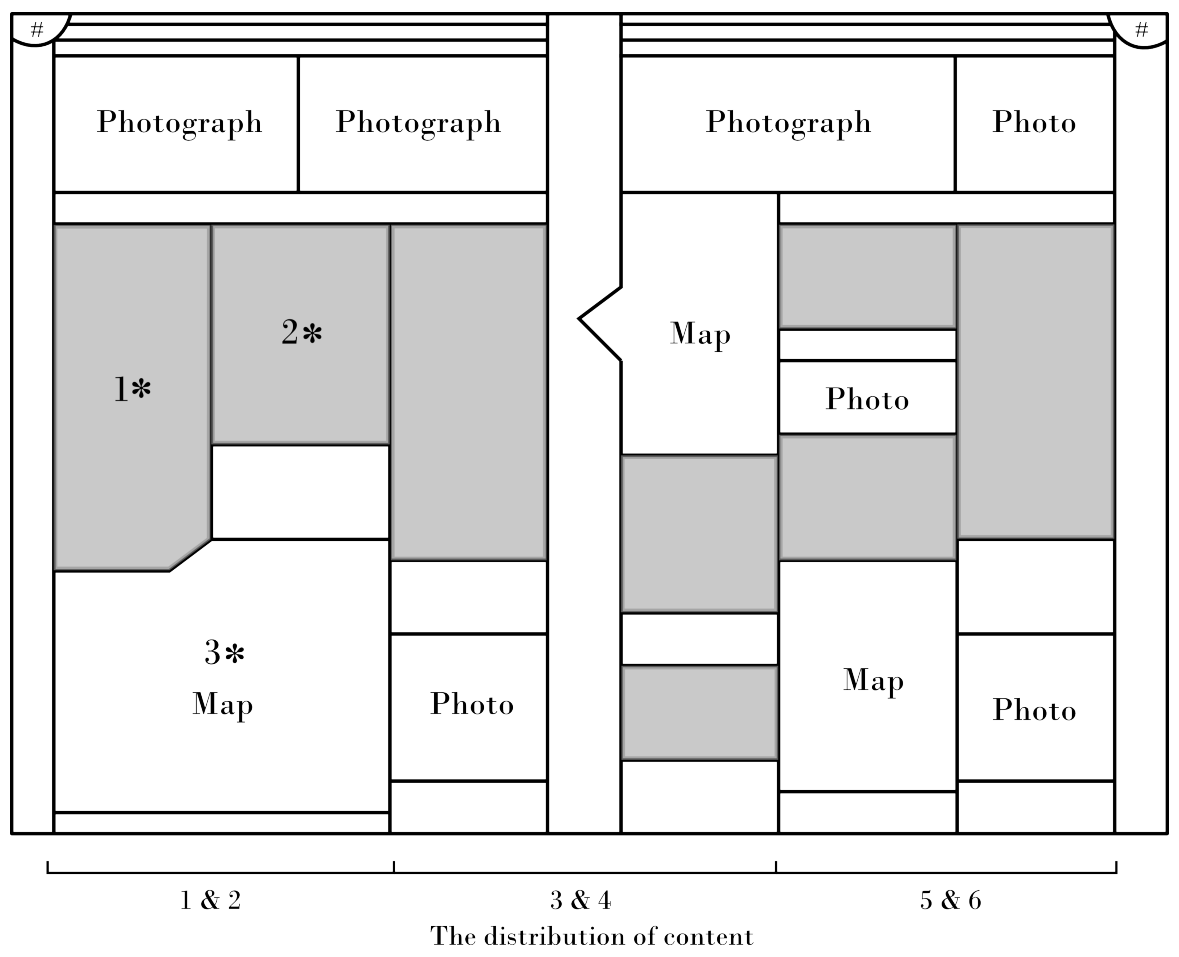

Fig. 4 Helsinki Your Way (2006)

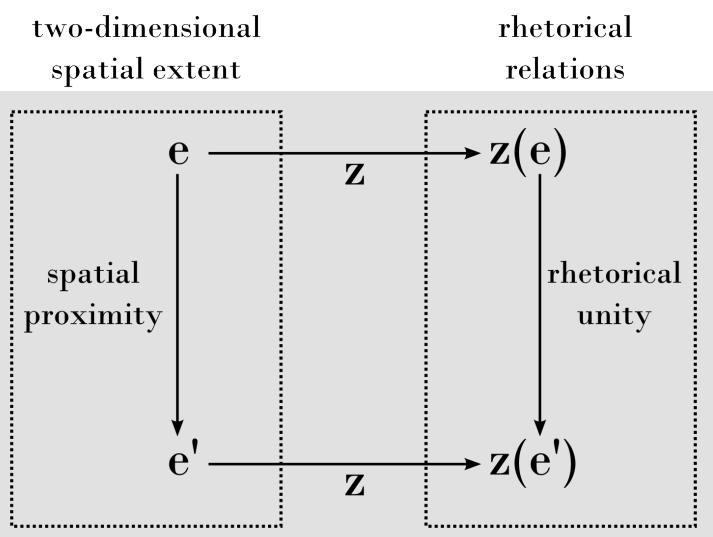

Fig. 5 Formalized discourse semantics for images and captions in Fig. 3

words and images can vary considerably.

The 'visual turn' in communication has been previously discussed, for example, in pedagogy (Kress 1998) and visual rhetoric (Kostelnick \& Hassett 2003). A common assumption is that the visual turn involves an increase of the visual elements at the cost of their verbal counterparts. However, Figs. 2, 3 and 4 show a different 
development: the layout space allocated to images decreases over time. Although the three brochures constitute a limited sample, they may be used to analyze the integration of the content in the layout (cf. Kong 2006, p. 222). For this purpose, we need the rhetorical component of the GeM model.

\subsection{The interface between layout and rhetorical structure}

The GeM model uses an extension of the Rhetorical Structure Theory (hereafter RST; see Mann \& Thompson 1988, Taboada \& Mann 2006) to describe how multimodal artefacts organize and argue for their content (Bateman 2008, p. 147-151). Fig. 6 provides a representation of the rhetorical structure in Figs. 2, 3 and 4. The analysis shows the different rhetorical segments and their interrelations. Due to limited space, each segment, such as 'description' and 'travel information', may include multiple RST segments with individual relations holding between them, which have not been expanded in Fig. 6. The rhetorical relations, such as ELABORATION, are marked with small capitals (for definitions and criteria for each relation, see Bateman 2008, p. 149).

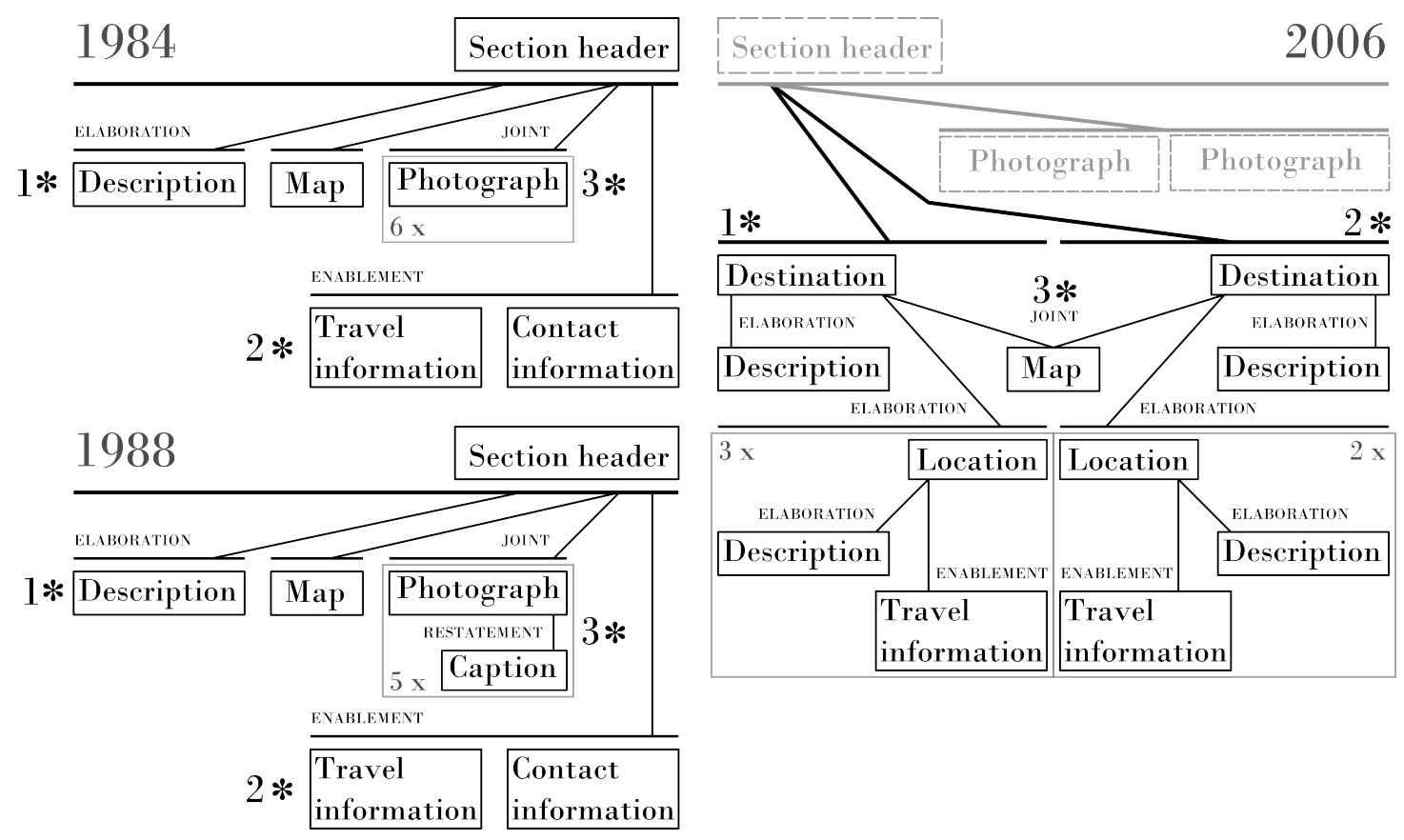

Fig. 6 RST descriptions of Figs. 2, 3 and 4

To begin with, all three examples exhibit similar patterns in their rhetorical structure: 'description' segments elaborate the described location, while 'travel and contact information' provide guidance and additional information. These basic 
functions of describing and informing are supported by photographs and maps (cf. Molina \& Esteban 2006, p. 1050). What Figs. 2, 3 and 4 show, however, is that the distribution of content in the layout varies, which suggests that the underlying rhetorical structure may be realized using different layout configurations. For a comparison of the content and its placement in the layout, see the corresponding identifiers $1^{*}, 2^{*}$ and $3^{*}$ in Fig. 6 and in Figs. 2, 3 and 4. I argue that this involves making selections in the semiotic modes that relate to both layout and rhetorical structure.

Let us begin with the examples from 1984 and 1988. As Fig. 6 shows, their rhetorical structure is similar, but their use of layout space differs considerably (see Figs. 2 and 3). The major difference is the introduction of captions to complement the images in the 1988 example. As Fig. 3 shows, implementing captions involves selections in both rhetorical and layout structures, because captions require an accompanying visual element and additional layout space for their realization. I suggest that these combinations in Fig. 3, indicated by the photographs $\left(3^{*}\right)$ and the grey areas below them, signal a move away from text-flow and its sequential organization, because the discourse semantic interpretation of these image-text combinations relies on spatial proximity (see Fig. 5).

Finally, I argue that the example from 2006 already uses the semiotic mode of page-flow. As Fig. 6 shows, the example includes two RST segments ( $1^{*}$ and $\left.2^{*}\right)$, which introduce a destination and describe several locations within it. These descriptions are realized using text-flow (see Fig. 4). In addition, a map $\left(3^{*}\right)$ that complements both descriptions $1^{*}$ and $2^{*}$ is incorporated into the rhetorical structure of these descriptive segments. I suggest that this shows a move towards page-flow, because the correct interpretation that places the elements $1^{*}, 2^{*}$ and $3^{*}$ together relies on the same principle of proximity that was set out in Fig. 5. In other words, the rhetorical connection between the descriptive segments $1^{*}, 2^{*}$ and the map $3^{*}$ is established by their spatial proximity.

The argument for page-flow is supported by the overall organization of the content in Fig. 4. The guideline below the area model shows the division of content into three columns, marked $1 \& 2,3 \& 4$ and $5 \& 6$, which extend across the 'traditional' page border between columns $3 \& 4$. In this case, it seems that pageflow is used to communicate extensive information within limited space, which consequently leads to a highly integrated multimodal structure.

\section{Discussion}

I will now discuss the implications of this paper to modelling the prototypical structure of a tourist brochure in a full-scale corpus study. In my ongoing doctoral dissertation, I aim to include data from up to 80 brochures published between 1967 
and 2008. Based on the observations in this paper, I will now present two points that need to be accounted for in the corpus analysis.

Firstly, it is necessary to define criteria for identifying the deployment of different semiotic modes in the corpus. The GeM-annotated corpus allows us to identify the structural signals that indicate the deployment of a specific semiotic mode in the tourist brochures, while simultaneously mapping the range of alternative configurations of the semiotic mode. On the basis of this paper, it may be suggested that the extension of rhetorical relations across layout areas in the area model may be a candidate signal for page-flow (see Figs. 4 and 6). However, the validity of each claim needs to be checked against the corpus.

Secondly, the results of this paper strongly advocate that the analysis of any static multimodal artefact should be approached from multiple perspectives. For instance, capturing the relationship between the rhetorical and layout structure requires the contribution of two analytical layers of the GeM model. This relationship, which could not be detected using a single analytical layer, may be characterized as reciprocal. In other words, this means that semiotic choices concerning the layout also affect the rhetorical structure, and vice versa.

Finally, I wish to emphasize the importance of conducting further research on the generic structure of multimodal artefacts. If multimodal research wishes to contribute to emerging concerns such as 'visual literacy', it needs to be able to produce reliable and comprehensive analyses to support any claims with pedagogical implications. What is thus required is an expansion of analytical foci to cover the middle range between detailed and abstract analyses by providing a strong, structural basis for any abstract theoretical concept deployed in the analysis.

\section{Acknowledgements}

I would like to thank Ivan Berazhny and the two anonymous reviewers for their insightful comments on earlier drafts of this paper.

\section{References}

Bateman, J. A. (2008), Multimodality and Genre: A Foundation for the Systematic Analysis of Multimodal Documents, Palgrave Macmillan, London.

Bateman, J. A. (2009), Discourse across semiotic modes, in J. Renkema, ed., 'Discourse, of course: An overview of research in discourse studies', Benjamins, Amsterdam/Philadelphia, pp. 55-66.

Bateman, J. A. (2011), The decomposability of semiotic modes, in K. L. O'Halloran \& B. A. Smith, eds, 'Multimodal Studies: Multiple Approaches and Domains', Routledge Studies in Multimodality, Routledge, London, pp. 17-38. 
Bateman, J. A. (forthcoming), Genre in the age of multimodality: some conceptual refinements for practical analysis, in P. Evangelisti-Allori, V. K. Bhatia \& J. A. Bateman, eds, 'Evolution in Genres: Emergence, Variation, Multimodality', Peter Lang. Scheduled winter 2012.

Bateman, J. A., Delin, J. L. \& Henschel, R. (2004), Multimodality and empiricism: preparing for a corpus-based approach to the study of multimodal meaning-making, in E. Ventola, C. Charles \& M. Kaltenbacher, eds, 'Perspectives on Multimodality', Benjamins, Amsterdam, pp. 65-89.

Cheong, Y. Y. (2004), The construal of ideational meaning in print advertisements, in K. L. O'Halloran, ed., 'Multimodal Discourse Analysis: Systemic Functional Perspectives', Continuum, London, pp. 163-195.

Delin, J., Bateman, J. A. \& Allen, P. (2003), 'A model of genre in document layout', Information Design Journal 11(1), 54-66.

Elleström, L. (2010), The modalities of media: A model for understanding intermedial relations, in L. Elleström, ed., 'Media Borders, Multimodality and Intermediality', Palgrave, London, pp. $11-48$.

Forceville, C. (2007), 'Book review: Multimodal Transcription and Text Analysis: A Multimedia Toolkit and Coursebook', Journal of Pragmatics 39(6), 1235-1238.

Francesconi, S. (2011), 'Images and writing in tourist brochures', Journal of Tourism and Cultural Change 9(4), 341-356.

Guijarro, A. J. (2011), 'Engaging readers through language and pictures: A case study', Journal of Pragmatics 43(12), 2982-2991.

Guijarro, A. J. \& Pinar Sanz, M. J. (2008), 'Compositional, interpersonal and representational meanings in a children's narrative: A multimodal discourse analysis', Journal of Pragmatics 40(9), 1601-1619.

Guo, L. (2004), Multimodality in a biology textbook, in K. L. O'Halloran, ed., 'Multimodal Discourse Analysis: Systemic Functional Perspectives', Continuum, London, pp. 196-219.

Halliday, M. A. K. (1978), Language as a Social Semiotic: The Social Interpretation of Language and Meaning, Arnold, London.

Halliday, M. A. K. \& Matthiessen, C. M. I. M. (2004), An Introduction to Functional Grammar, third edn, Arnold, London.

Held, G. (2005), 'Magazine covers - a multimodal pretext-genre', Folia Linguistica XXXIX(12), 173-196.

Hiippala, T. (2007), Helsinki: A multisemiotic analysis of tourist brochures, Master's thesis, University of Helsinki.

Hiippala, T. (2012a), The localisation of advertising print media as a multimodal process, in W. L. Bowcher, ed., 'Multimodal Texts from Around the World: Linguistic and Cultural Insights', Palgrave, London, pp. 97-122.

Hiippala, T. (2012b), 'Reading paths and visual perception in multimodal research, psychology and brain sciences', Journal of Pragmatics 44(3), 315-327.

Hofinger, A. \& Ventola, E. (2004), Multimodality in operation: language and picture in a museum, in E. Ventola, C. Charles \& M. Kaltenbacher, eds, 'Perspectives on Multimodality', Benjamins, Amsterdam, pp. 193-210.

Holsanova, J. \& Nord, A. (2010), Multimodal design: Media structures, media principles and users meaning-making in printed and digital media, in H.-J. Bucher, T. Gloning \& K. Lehnen, eds, 'Neue Medie - neue Formate: Ausdifferenzierung und Konvergenz in der Medienkommunikation', Campus, Frankfurt/New York, pp. 81-103.

Jewitt, C. (2009), Different approaches to multimodality, in C. Jewitt, ed., 'The Routledge Handbook of Multimodal Analysis', Routledge, London, pp. 28-39. 
Kong, K. (2006), 'A taxonomy of the discourse relations between words and visuals', Information Design Journal 14(3), 207-230.

Kostelnick, C. \& Hassett, M. (2003), Shaping Information: The Rhetoric of Visual Conventions, Southern Illinois University Press, Carbondale.

Kress, G. (1998), Visual and verbal modes of representation in electronically mediated communication: the potentials of new forms of text, in I. Snyder, ed., 'Page to Screen: Taking Literacy into the Electronic Era', Routledge, London and New York, pp. 53-79.

Kress, G. (2009), What is mode?, in C. Jewitt, ed., 'The Routledge Handbook of Multimodal Analysis', Routledge, London, pp. 54-67.

Kress, G. (2010), Multimodality: A Social Semiotic Approach to Contemporary Communication, Routledge, London.

Kress, G. \& van Leeuwen, T. (2002), 'Colour as a semiotic mode: notes for a grammar of colour', Visual Communication 1(3), 343-368.

Kress, G. \& van Leeuwen, T. (2006), Reading Images: The Grammar of Visual Design, second edn, Routledge, London.

Kvåle, G. (2010), Invitasjon til destinasjon: Multimodal retorikk i turistkommunikasjon, in M. Engebretsen, ed., 'Skrift/bilde/lyd: Analyse av sammensatte tekster', Høyskoleforlaget, Kristiansand, pp. 39-55.

Mann, W. C. \& Thompson, S. A. (1988), 'Rhetorical Structure Theory: Toward a functional theory of text organization', Text 8(3), 243-281.

Martinec, R. (2003), 'The social semiotics of text and image in [j]apanese and [e]nglish software manuals and other procedures', Social Semiotics 13(1), 43-69.

Martinec, R. \& Salway, A. (2005), 'A system for image-text relations in new (and old) media', Visual Communication 4(3), 337-371.

Molina, A. \& Esteban, A. (2006), 'Tourism brochures: Usefulness and image', Annals of Tourism Research 33(4), 1036-1056.

O'Halloran, K. L. (2008), 'Systemic functional-multimodal discourse analysis (SF-MDA): Constructing ideational meaning using language and visual imagery', Visual Communication $7(4), 443-475$.

O'Halloran, K. L., ed. (2004), Multimodal Discourse Analysis: Systemic Functional Perspectives, Continuum, London.

O'Halloran, K. L. \& Lim, F. V. (2009), Sequential visual discourse frames, in E. Ventola \& A. J. Guijarro, eds, 'The World Told and the World Shown: Multisemiotic Issues', Palgrave, London, pp. 139-156.

O'Halloran, K. L., Tan, S., Smith, B. A. \& Podlasov, A. (2010), 'Challenges in designing digital interfaces for the study of multimodal phenomena', Information Design Journal 18(1), 2-21.

O'Halloran, K. L., Tan, S., Smith, B. A. \& Podlasov, A. (2011), 'Multimodal analysis within an interactive software environment: critical discourse perspectives', Critical Discourse Studies 8(2), 109-125.

O'Toole, M. (2010), The Language of Displayed Art, second edn, Routledge, New York.

Parodi, G. (2010), 'Research challenges for corpus cross-linguistics and multimodal texts', Information Design Journal 18(1), 69-73.

Reichenberger, K., Rondhuis, K., Kleinz, J. \& Bateman, J. A. (1996), Effective presentation of information through page layout: a linguistically-based approach, Technical Report Arbeitspapiere der GMD 970, Institut für Integrierte Publikations- und Informationssysteme (IPSI), GMD, Darmstadt.

URL: http://www.cs.uic.edu/ifc/mmwsproc/reichen/page-layout.html

Royce, T. D. (1998), 'Synergy on the page: Exploring intersemiotic complementarity in page- 
based multimodal text', JASFL Occasional Papers 1(1), 25-49.

Smith, B. A., Tan, S., Podlasov, A. \& O'Halloran, K. L. (2011), 'Analyzing multimodality in an interactive digital environment: Software as metasemiotic tool', Social Semiotics 21(3), 369380.

Stenglin, M. (2009), Space and communication in exhibitions: Unravelling the nexus, in C. Jewitt, ed., 'The Routledge Handbook of Multimodal Analysis', Routledge, London, pp. 272-283.

Taboada, M. \& Mann, W. C. (2006), 'Rhetorical structure theory: looking back and moving ahead', Discourse Studies 8(3), 423-459.

Thomas, M. (2007), Querying multimodal annotation: A concordancer for GeM, in 'Proceedings of the Linguistic Annotation Workshop', Association for Computational Linguistics, Prague, Czech Republic, pp. 57-60.

URL: $h t t p: / / w w w . a c l w e b . o r g / a n t h o l o g y / W / W 07 / W 07-1510$

Thomas, M. (2009a), Developing multimodal texture, in E. Ventola \& A. J. Guijarro, eds, 'The World Told and the World Shown: Multisemiotic Issues', Palgrave, London, pp. 39-55.

Thomas, M. (2009b), Localizing pack messages: A framework for corpus-based cross-cultural multimodal analysis, $\mathrm{PhD}$ thesis, University of Leeds.

van Leeuwen, T. (1993), 'Genre and field in critical discourse analysis: a synopsis', Discourse and Society 4(2), 193-223.

van Leeuwen, T. (2005a), Introducing Social Semiotics, Routledge, London.

van Leeuwen, T. (2005b), Multimodality, genre and design, in S. Norris \& R. H. Jones, eds, 'Discourse in Action: Introducing Mediated Discourse Analysis', Routledge, London, pp. 7394.

van Leeuwen, T. (2011), The Language of Colour: An Introduction, Routledge, London.

White, P. (2010), 'Grabbing attention: the importance of modal density in advertising', Visual Communication 9(4), 371-397. 